European Association for the Development of Renewable Energies, Environment and Power Quality (EA4EPQ)
International Conference on Renewable Energies and Power

Quality (ICREPQ'10)

Granada (Spain), 23rd to 25th March, 2010

\title{
MODELING AND ANALYSIS OF A TRACTION CONTROL SYSTEM FOR TWO INDEPENDENT WHEEL DRIVES-ELECTRIC VEHICLE
}

\author{
S. M. Wasfy ${ }^{1}$, M.M.Eissa ${ }^{1,2}$ (SMIEEE), G.M.A.Sowilam ${ }^{1}$, M.Abdel monem ${ }^{1}$ \\ ${ }^{1}$ Electrical Power \& Machines Department \\ HelwanUniversity, Helwan (Egypt) \\ Phone:+002 0102982296, e-mail: abdelmonem_82@yahoo.com \\ ${ }^{2}$ Faculty of Engineering, Electrical Engineering Department, \\ with King Abdul-Aziz University, Jeddah 21415, Saudi Arabia
}

\begin{abstract}
This paper presents a detailed dynamic model of an electric vehicle with two independent wheel drives and an improved traction control system. The present research demonstrates a model and analysis of a traction control system for two independent wheels drives electric vehicles. An electrical differential was implemented assuring that in a straight trajectory, the two rear wheels run exactly at the same speed (for a steering angle equals zero) and for the same road conditions under the left and right side of wheels. However, an electrical differential with the control strategy is established due to:

1- When the vehicle turns right and left, the references for the rear speeds are selected according to the steering angle, to ensure that during turning the wheels will maintain the relative speeds imposed by the trajectory geometry.

2- When the motor is tested with two different subclasses of four quadrant of DC/DC chopper voltage to study the method for developing energy saving.

With the information about the real speed of the vehicle, on left and right sides, the control algorithm changes the generated torques in each wheel drive, in order to produce the same traction force applied to the road surface.
\end{abstract}

Keywords. Electric vehicle, energy saving, electric differential, Simulation and control.

\section{INTRODUCTION}

Recently electric vehicles (EVs) including fuel-cell and hybrid vehicles have been developed very rapidly as a solution of energy and environmental problems.

Since electric motors and DC chopper are utilized in drive system, they have great advantages over internal combustion engine vehicles (ICVs) such as quick and comprehensible torque response and individual control of each wheel and mechanical components reduction and allowing a better performance.

The usual configuration of electrical or non-electrical vehicles presents only one traction motor driving two wheels, using a differential gear. In this paper, a structure of vehicle was adapted allowing to obtain a vehicle with two independent wheel drives see Fig.(1).

A first step in reduction of mechanical transmission components is related to the elimination of the mechanical differential gear introducing an electronic substitute system, called electrical differential.

These systems objectives can be implemented in EV's in a much more easier and adapted way. The natural ability of electric drives to control the generated torque and the introduce an independent control of the traction wheel drives (two or four) can allow high performance traction control with a low cost, a quick response and easy to design implementation. A vehicle topology like the proposed one allows a simplified mechanical structure of the vehicle and an effective traction control will allow to reduced the energy consumption, namely by diminishing energy losses from the friction between the tires and the road surface during sliding, improving the tires lifetime. The paper [1] and [2] show that with two wheel drives and two independent motors, it is possible to eliminate the mechanic differential and implement an electric differential, Now, in this paper the proposed system some assumption taken in that as:

- The uses of P-D controller with logic control and sensor control to analyze the possible sliding of the vehicle. With the acquisition of this value, the torque in each wheel could be controlled.

- The adhesion coefficients on the left and right side of the vehicle could be different. Therefore, it is necessary making possible the steerability and stability of the vehicle, that is the task of the traction control algorithm to be introduced.

- Simulation result will concentrate on the following: 1- Two different subclasses of four quadrant of DC/DC chopper voltage to study the method for developing energy saving.

2- When the vehicle turns right and left. 


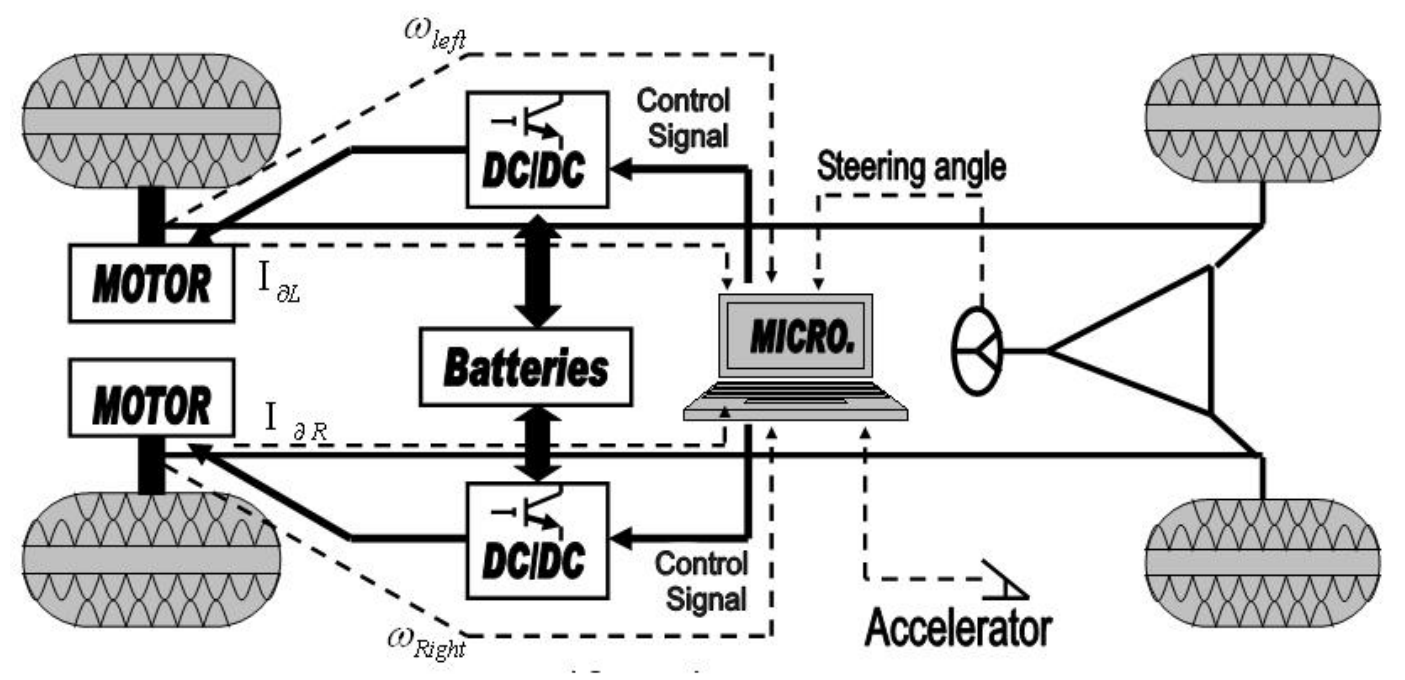

Fig. 1. Configuration Of Proposed Electric Vehicle.

\section{VEHICLE DYNAMIC ANALYSIS}

In the dynamic analysis of the vehicle behavior, it is considered that the front wheels are free. At the beginning it is assumed that, at each drive wheel is applied an equal influence from the vehicle mass and from the external forces.

\section{A. Forces applied to the vehicle structure}

If the DC motors have the same armature current, the produced torqueses are the same and the applied forces to the ground. In this situation the left and right wheels rolls at the same speed and the vehicle has a straight trajectory.

Total Load Force $F_{T}$,[2] and [5] : This force is the sum of the rolling resistance $\left(F_{R R}\right)$, stokes force or viscous friction $\left(F_{S T}\right)$, aerodynamic drag $\left(F_{A D}\right)$ and climbing resistance $\left(F_{C R}\right)$.

$F_{T}=F_{R R}+F_{S T}+F_{A D}+F_{C R}$

$F_{R R}, F_{S T}, F_{A D}$ and $F_{C R}$ can be given as:

$F_{R R}=\mu * M * g$

$F_{S T}=K_{S} * v_{v}$

$F_{A D}=K_{D} * v_{v}^{2}$

$F_{C R}=M * g * \sin (\alpha)$

Where: $\mu$ is the rolling resistance coefficient (caused by the tire deformation and contact with road), $M$ is the vehicle mass and $\mathrm{g}$ is the gravitational acceleration constant, $K_{S}$ is the stokes coefficient and $v_{v}$ is the linear velocity of the vehicle and $K_{D}$ is the aerodynamic drag coefficient.

Fig.(2) shows the force applied to the vehicle when the road slope $(\alpha)$ increase than zero, where $\mathrm{P}=\mathrm{M}^{*} \mathrm{~g}$.

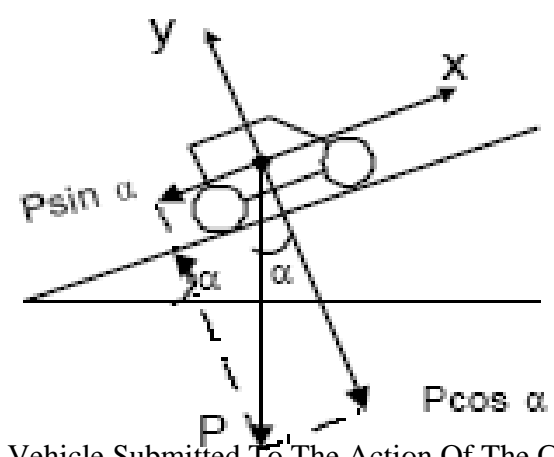

Fig. 2. Vehicle Submitted To'The Action Of The Climbing Force

\section{B. Wheel Dynamics}

The mechanical equation given in [1] and [2] is used to describe each wheel drive as:

$J_{m} * \frac{d \omega_{m}}{d t}=T_{m}-T_{r}$

Where $J_{m}$ is the moment of inertia of the vehicle from the motor referential, $\omega_{m}$ is the angular motor velocity, $T_{m}$ is the produced motor torque.

$\omega_{m}=\omega_{\text {wheel }}$

$T_{m}=T_{\text {wheel }}$

The load torque of the motor referential is:

$T_{r}=F_{T} * r$

where $r$ is the radius of wheel. 
The global moment of inertia of the vehicle from the motor referential $\left(J_{m}\right)$, can be defined as a sum of shaft inertia moment ( $J_{\text {wheel }}$ ) and inertia moment of the vehicle $\left(J_{v}\right)$ :

$$
J_{m}=\mathrm{J}_{\text {wheel }}+J_{v}
$$

The moment of inertia of wheel is:

$$
J_{\text {wheel }}=0.5 * r^{2} * M_{\text {wheel }}
$$

The moment of inertia of vehicle is:

$$
J_{v}=0.5 * M * r^{2} *(1-\operatorname{slip})
$$

In order to make traction control, it is necessary to know the linear velocity of each drive wheel $\left(v_{\text {wheel }}\right)$ and the real linear velocity of the vehicle on both sides $\left(v_{v}\right)$.

It is possible to calculate the slip (the relation speed differences between $v_{\text {wheel }}$ and $v_{v}$ ) as;

$$
\operatorname{Slip}=\left|\frac{v_{\text {wheel }}-v_{v}}{\max \left\{v_{\text {wheel }}, v_{v}\right\}}\right|
$$

Slip presents linear velocity difference between vehicle and wheel, slip value used to calculate The moment of inertia of vehicle equation (12).

\section{Speed of the Vehicle}

If the left side of angular velocity of the vehicle $\left(v_{L}\right)$ is equal to the right side of angular velocity $\left(v_{R}\right)$, then the vehicle angular velocity $\left(v_{v}\right)$ can be considered equal to those angular velocities.

$$
v_{v}=\frac{v_{L}+v_{R}}{2}
$$

the acceleration of the right side of the vehicle is:

$$
a_{R}=\frac{2}{M} *\left(F_{R}-\frac{F_{T}}{2}\right)
$$

Then the right side angular velocity of the vehicle is expressed as:

$$
v_{R}=\int_{0}^{t} a_{R} d t
$$

As the same manner, the acceleration and velocity of the left side of the vehicle can be expressed as:
$a_{L}=\frac{2}{M} *\left(F_{L}-\frac{F_{T}}{2}\right)$

$v_{R}=\int_{0}^{t} a_{L} d t$

Equations (15), equation (16), equation (17) and equation (18) present the manner to implement the velocity of each side of vehicle depending on total forces, which effect on vehicle

\section{SYSTEM DESCRIPTION}

Fig.(3) presents the vehicle structure during cornering, where $\mathrm{L}$ represents the wheelbase, $\delta$ is the steering angle and $\mathrm{d}$ is the distance between the wheels of the same axle and $\mathrm{R}$ the radius of curvature .

According to Fig (3), the linear velocity of each wheel drive is express as a function of the vehicle velocity and the radius of turn, presented by equations (19) and (20).

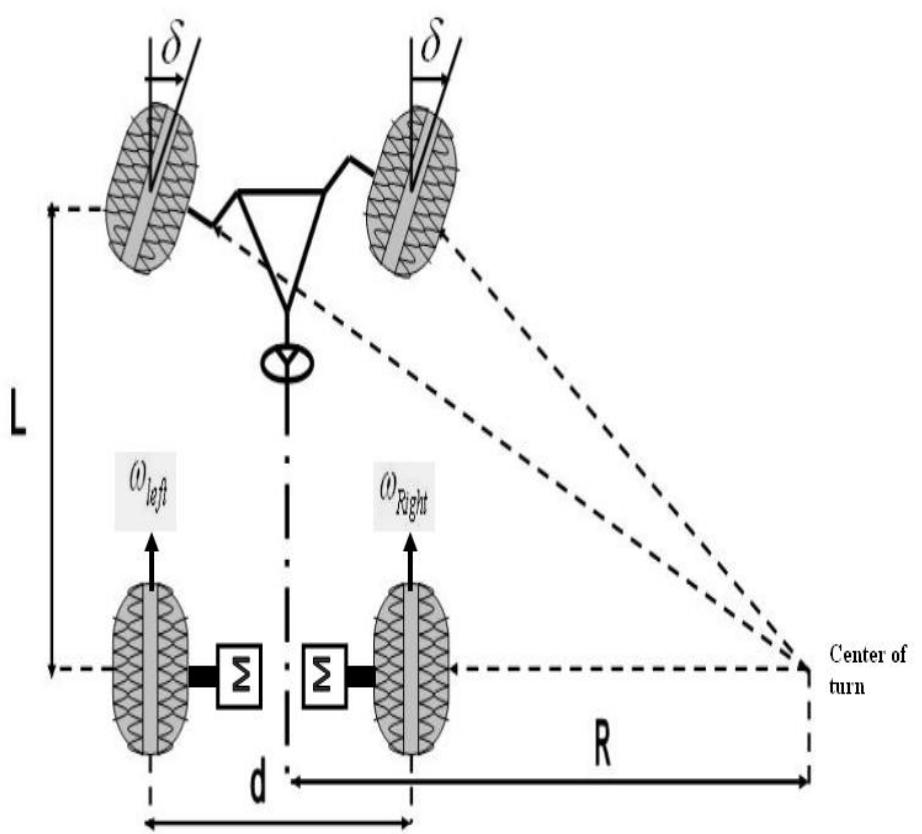

Fig. 3. Vehicle during cornering

$v_{L(\operatorname{Re} f)}=\omega_{V(\operatorname{Re} f)} *\left(R+\frac{d}{2}\right)$
$v_{R(\operatorname{Re} f)}=\omega_{V(\operatorname{Re} f)} *\left(R-\frac{d}{2}\right)$

The radius of curve depends on the wheelbase and steering angle given by:

$R=\frac{L}{\tan (\delta)}$

Substituting (21) in equations (19) and (20), angler velocity in each wheel drive can be obtained by: 
$\omega_{L(\operatorname{Re} f)}=\frac{L+\left(\frac{d}{2} * \tan (\delta)\right)}{L} * \omega_{V(\operatorname{Re} f)}$

$\omega_{R(\operatorname{Re} f)}=\frac{L-\left(\frac{d}{2} * \tan (\delta)\right)}{L} * \omega_{V(\operatorname{Re} f)}$

The difference between the angular velocity $\omega_{L(\operatorname{Re} f)}$ and $\omega_{R(\operatorname{Re} f)}$ of the wheel drives is expressed by equation (24).

The steering angle signal indicates the turn direction is given by the relationship of equation in (25).

$\Delta \omega=\omega_{L(\operatorname{Re} f)}-\omega_{R(\operatorname{Re} f)}=\frac{d * \tan (\delta)}{L} * \omega_{V(\operatorname{Re} f)}$

where $\omega_{V(\operatorname{Re} f)}$ is the reference of angular velocity of vehicle, which comes via the driver.

$$
\begin{aligned}
& \delta>0 \Rightarrow \text { Turn right } \\
& \delta=0 \Rightarrow \text { Straight line } \\
& \delta<0 \Rightarrow \text { Turn left }
\end{aligned}
$$

The angular velocity references $\omega_{L(\operatorname{Re} f)}$ and $\omega_{R(\operatorname{Re} f)}$ of the wheel drives are simulated and implemented [2]. Fig.(4) is a diagram that illustrates the vehicle electric differential depend on equation (21),(22),(23),(24) and (25), to conclude two output angular velocity references .

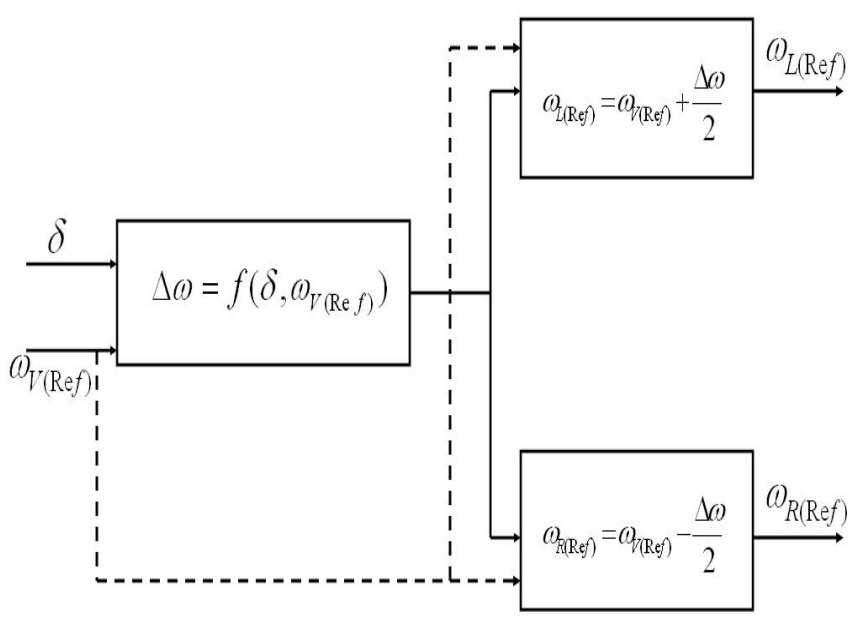

Fig.4. Electric differential diagram

\section{A. Global model of electrical drive}

Fig.(5) presents the block diagram of the proposed electrical drive system guarantee the different speeds of the wheel drives, the speed of each rear wheels is controlled using a feedback of the angular velocity of the two wheels drives $\left(\omega_{\text {Left }}, \omega_{\text {Right }}\right)$.

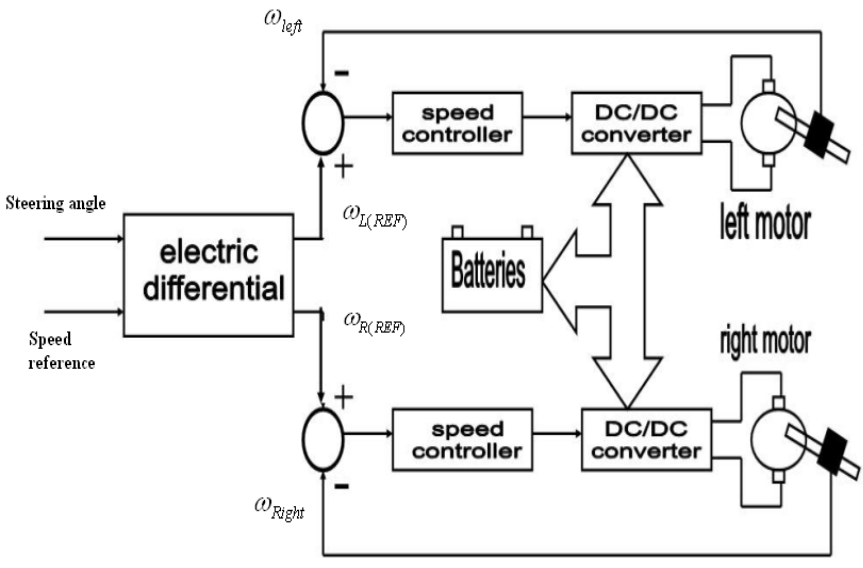

Fig 5: Proposed electrical.

The speed of each rear wheel is controlled using a feedback of angular velocity of the two rear wheels $\left(\omega_{\text {Left }}, \omega_{\text {Right }}\right)$. A PDcontroller is implemented in order to obtain null static error, between the reference for the angular velocity $\left(\omega_{L(\operatorname{Re} f)}, \omega_{R(\operatorname{Re} f)}\right)$, and the measured value $\left(\omega_{\text {Left }}, \omega_{\text {Right }}\right)$, as shown in fig. (6). The Variables $\mathrm{I}_{a L}, \mathrm{I}_{a R}$ are the two motor parameter currents are used in logic control method to make current limitations. Fig. (5). shows the angular velocities error ( $e_{\omega}=\omega_{\operatorname{Re} f}-\omega_{\text {actual }}$ ), that is the input to a proportionalderivative (PD) controller to obtain a switching function (S). The following equation (26) shows the operation of PD controller.

$S=\left(K_{P} * e_{\omega}\right)+\left(K_{D} * \frac{d e_{\omega}}{d t}\right)$

The purpose of the derivative action is to provide lead to overcome lags in the loop. In other words, it anticipates where the process proceeds by looking at the rate of change of error.

Fig. (7). and table (1) demonstrate the logical schematic diagram of the proposed controller system. The following equation (27) explains the logic control circuit that is shown in fig. (7), which is used after PD controller to make the following: By using $\left(a b s{ }_{i} i_{a}\right)$ and $\left(\operatorname{sgn} \_S\right.$ ) can obtain $\left(\operatorname{sgn} \_U_{a}\right)$ :

$$
\text { sgn_U } U_{a}=\left(\operatorname{sgn} \_S \wedge \overline{a b s \_i_{a}}\right)
$$

Convert the switching function (S) to signals (ones and zeros) presented by (sgn_ $S$ ).

To control motor current to be within suitable limits represented by $\left(a b s_{-} i_{a}\right)$.

The discontinuous voltage value is selected according to the switching function signal (sgn_ $S$ ). Including current limitation $\left(a b s_{-} i_{a}\right)$ is possible to have a new logic function that gives the chopper signal ( $\operatorname{sgn} \_U_{a}$ ). The results are shown in table (1).

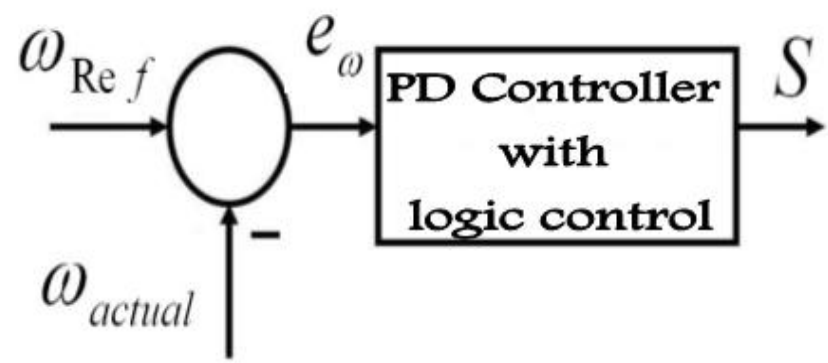

Fig 6: System control. 


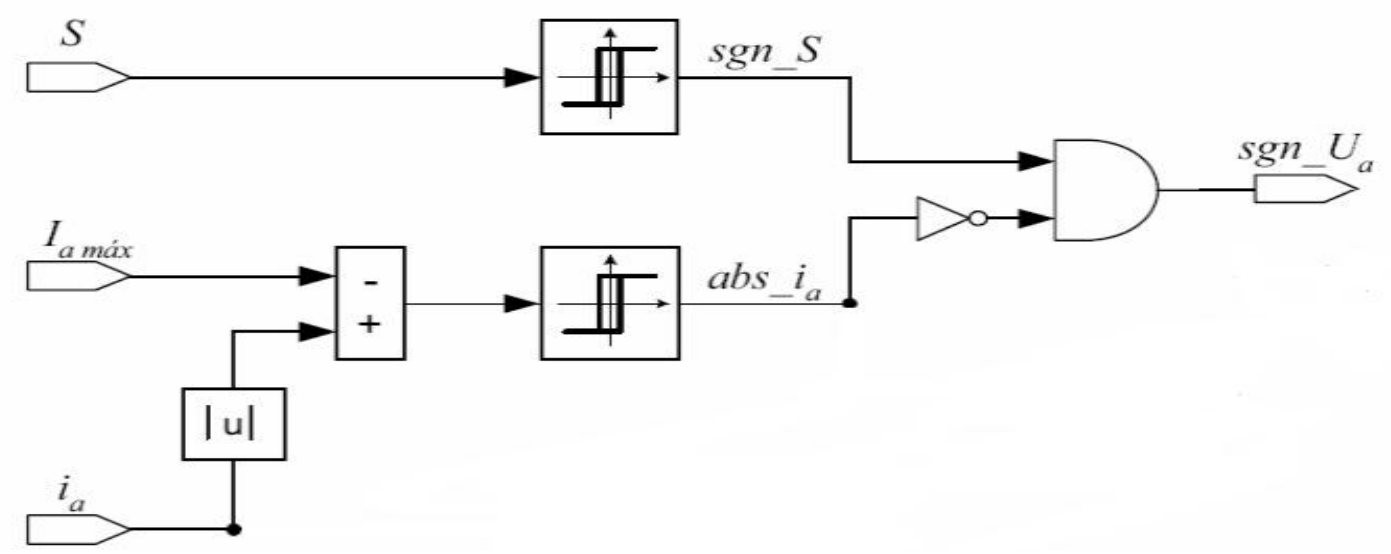

Fig.(7) Logical diagram to implement the switches signal.

\section{TABLE 1: Logic function of the armature voltage signal}

\begin{tabular}{|c|c|c|}
\hline sgn_S & $a b s_{-} i_{a}$ & $\operatorname{sgn} \_U_{a}$ \\
\hline 0 & 0 & 0 \\
\hline 1 & 0 & 1 \\
\hline 0 & 1 & 0 \\
\hline 1 & $\begin{array}{c}a b S_{-} i_{a}=1 \\
\text { when } \\
\text { sgn_ } S=1 \\
\text { when } \\
\text { error }>0\end{array}$ & $\begin{array}{c}\text { sgn_ } U_{a}=1 \\
\text { when } \\
i_{a} \mid-I_{a \text { max }}>0\end{array}$ \\
\hline
\end{tabular}

\section{SIMULATION RESULTS}

The proposed system is tested with two DC motor 3HP. The system is implemented by using Matlab simulation to obtain the following cases:

\section{Case(1) the motor is tested with two techniques:}

The first one, the output of the DC chopper has 2 level voltage (positive and zero) and the second, the output of the DC chopper has 2 level voltage (positive and negative).

Fig.(10) and Fig.(11) show the performance of motor under the first technique. Fig.(10-a) shows the output voltage of DC chopper, Fig(10-b) show the left motor armature current, Fig(10-c) show the right motor armature current and Fig(10-d) shows the speed difference between the two rear wheels. From second technique it is noticed that, the ripple content on current in Fig.(11-b),.(11-c)and (11-d) more than that of Fig.(10-b),(10c) and (10-d) but the energy consumed by two technique discussed as:
This study done during 15 sec:

Technique one study:

Total energy consumed in left motor $=5870.6$ watt.sec.

Total energy consumed in right motor $=5870.6$ watt.sec.

Total energy consumed in vehicle $=11741.2$ watt.sec.

Technique two study:

Total energy consumed in left motor $=5841.0$ watt.sec.

Total energy consumed in right motor $=5841.0$ watt.sec.

Total energy consumed in vehicle $=11682$ watt.sec.

From previous study, the second technique can be saved energy than first Technique. Saved energy $=11741.2-11682=59.2$ watt.sec.

\section{Case (2) Simulation result when turning the vehicle:}

Fig.(12-a) shows steering angle of vehicle during turn to right, steering angle is equal (zero degree) from beginning and after 4 second steering angle increased gradually until it reached to 52 degree after 6 second, and after 8 second steering angle beginning to decrease until it reached to zero degree again after 10 second. The same occurred for Fig.(13-a) when a vehicle turned to left but the steering angle after 6 second reached to 52 degree. When the steering angle beginning to increase above zero degree the right speed must be decreased as shown in Fig.(12-b), also the speed of left wheel must be increased as shown in Fig.(12-c) .result, the vehicle is tuned to right. When the steering angle beginning to decrease below zero degree the left speed must be decreased as shown in Fig.(13-c), also the speed of right wheel must be increased as shown in Fig.(13-b) .result, the vehicle is tuned to right.

Fig.(12-d),(12-e),(13-d) and (13-e) show an angular velocity error $(\mathrm{rad} / \mathrm{sec})$ between reference and actual angular velocity error of both side during turn to left and to right, as shown all angular velocity error not exceed than $(0.16 \mathrm{rad} / \mathrm{sec})$. 


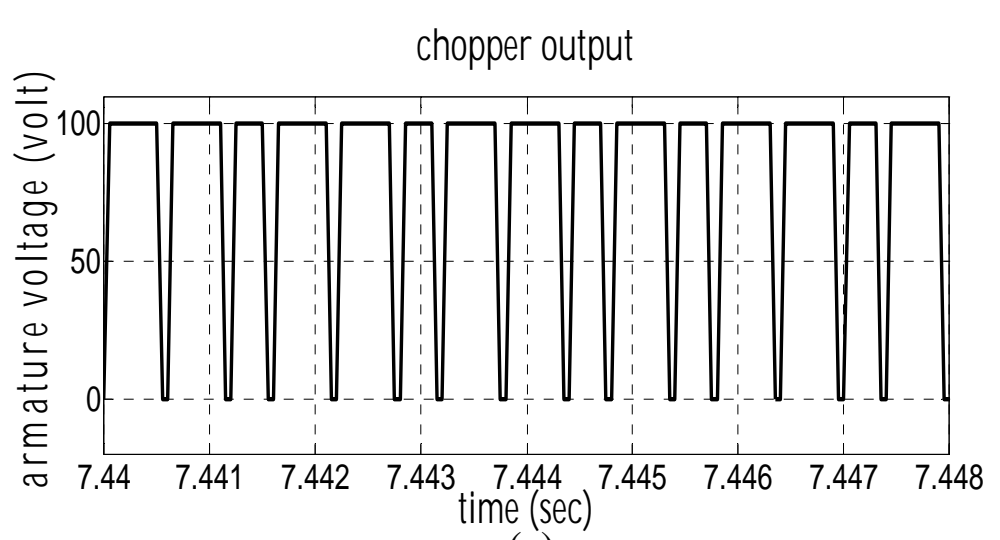

(a)

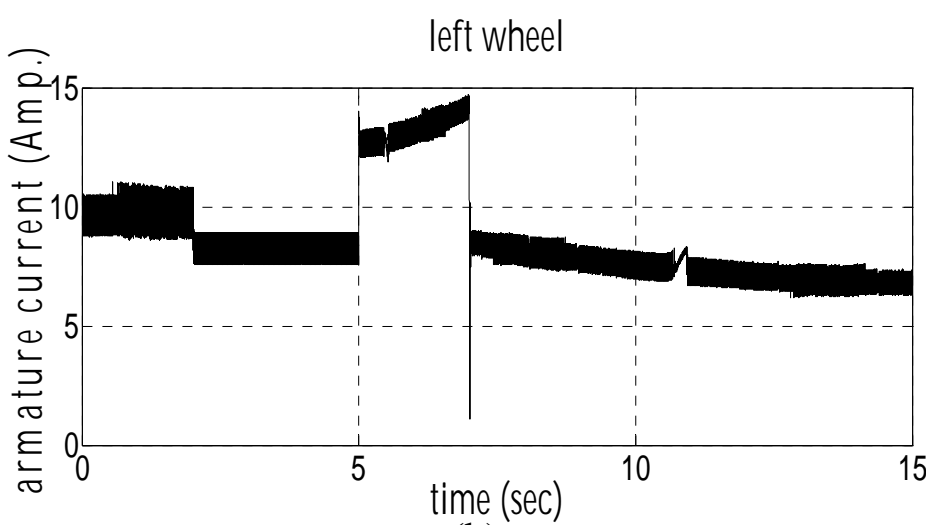

(b)

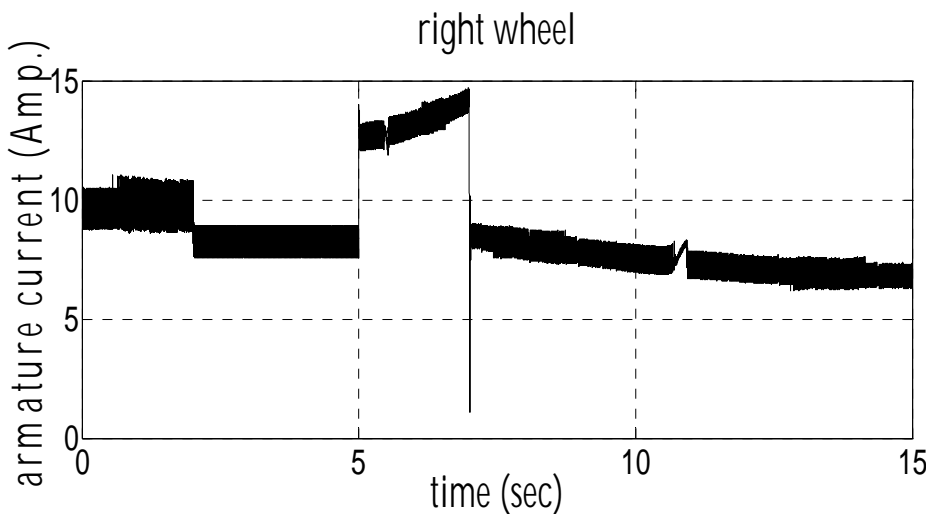

(c)

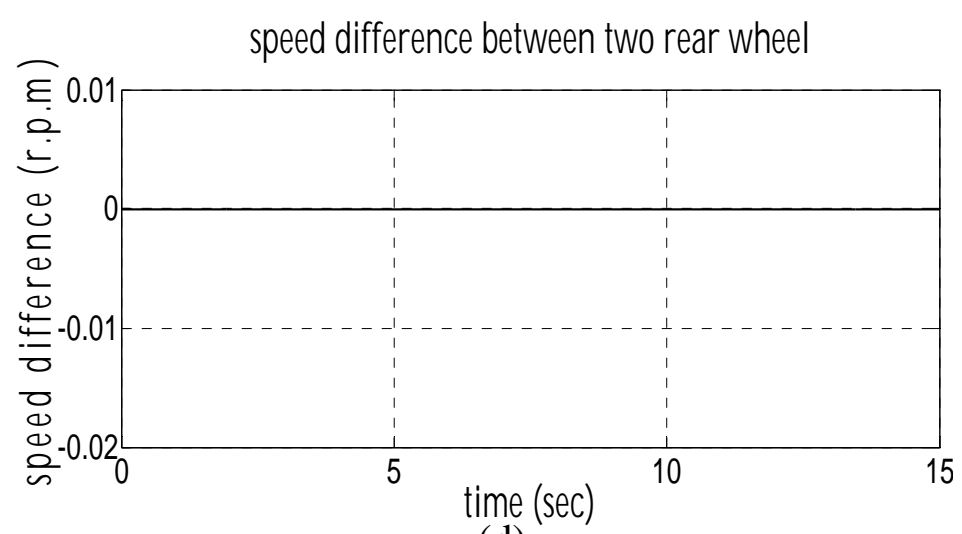

(d)

Fig 10: The chopper output when the output voltage of DC chopper is orientation in positive and zero

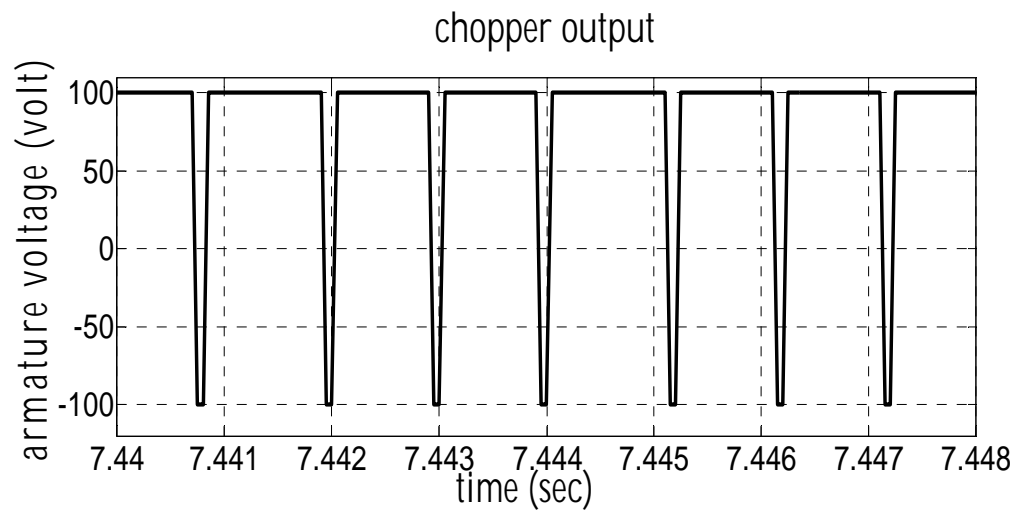

(a)

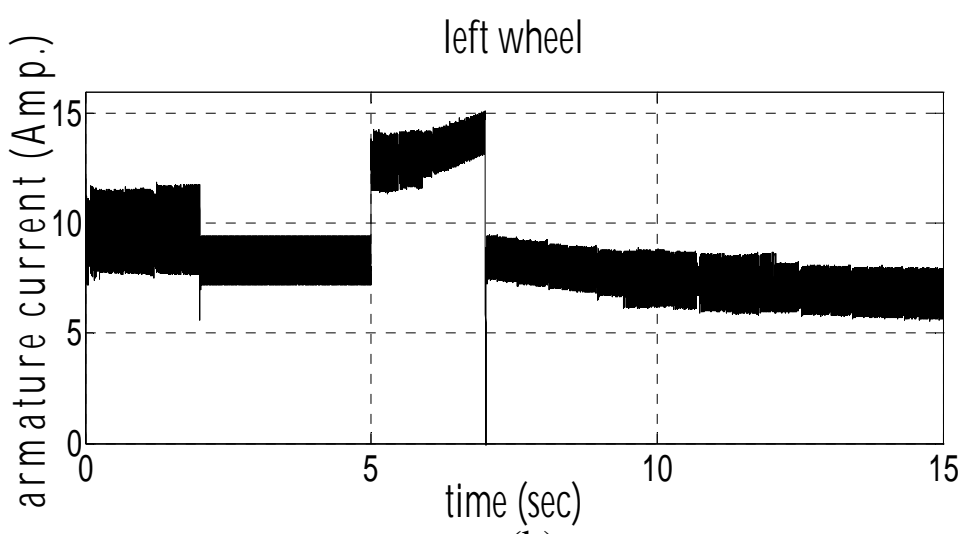

(b)

right wheel

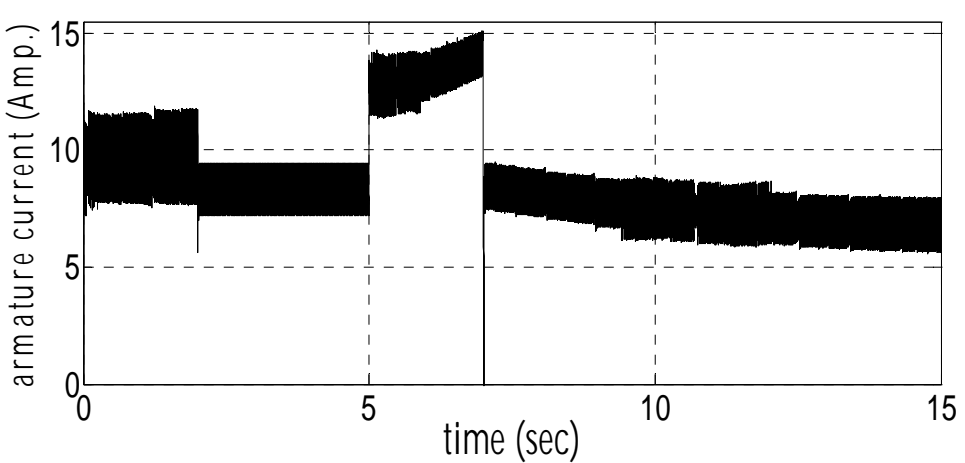

(c)

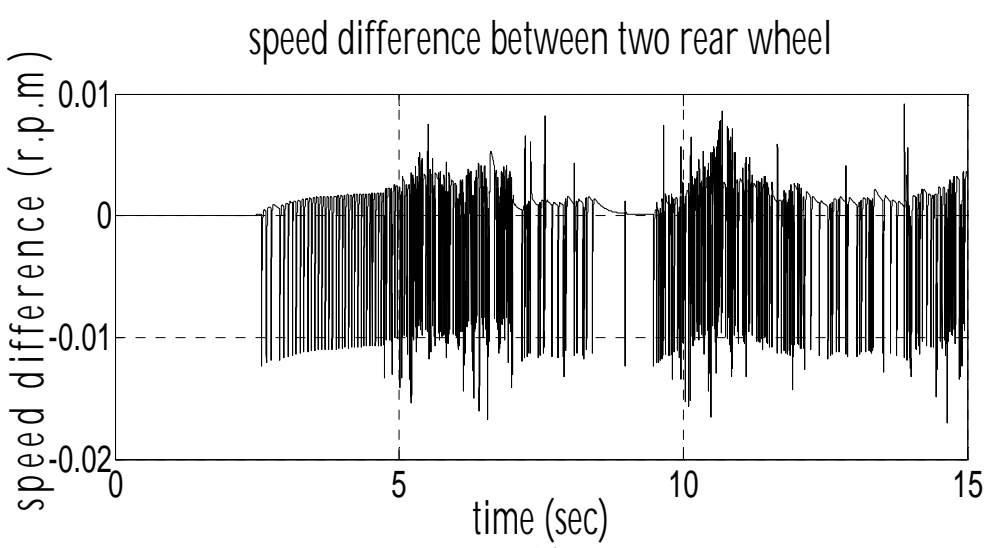

(d)

Fig 11: The chopper output when the output voltage of DC chopper is orientation in positive and negative 


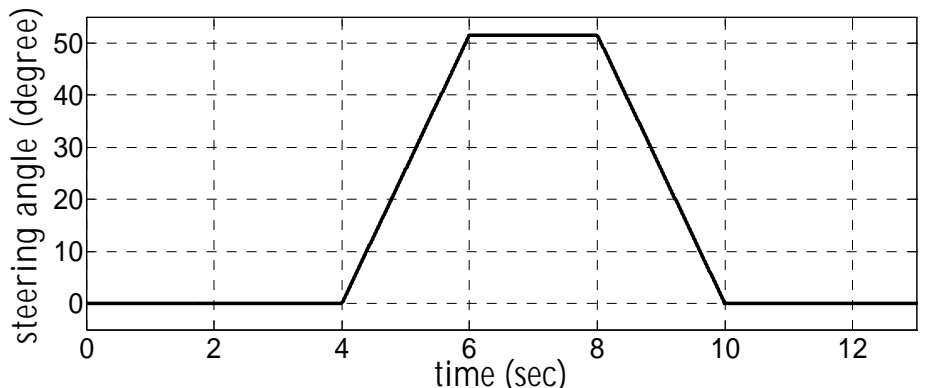

(a)

right wheel

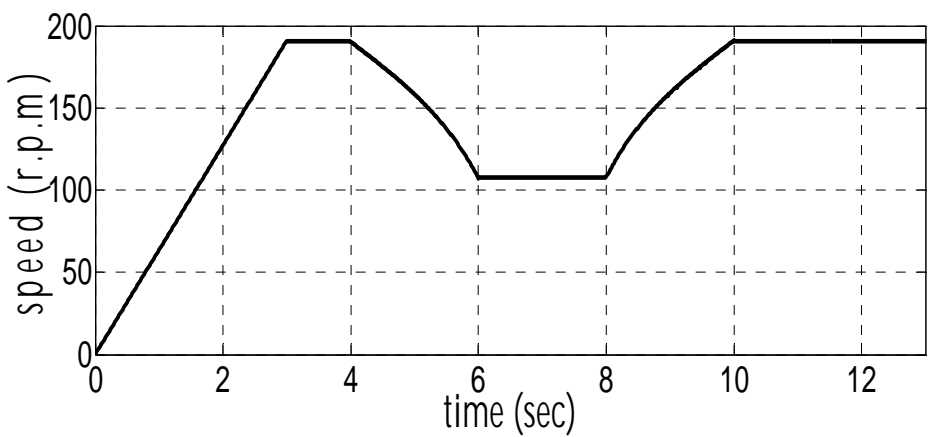

(b)

left wheel

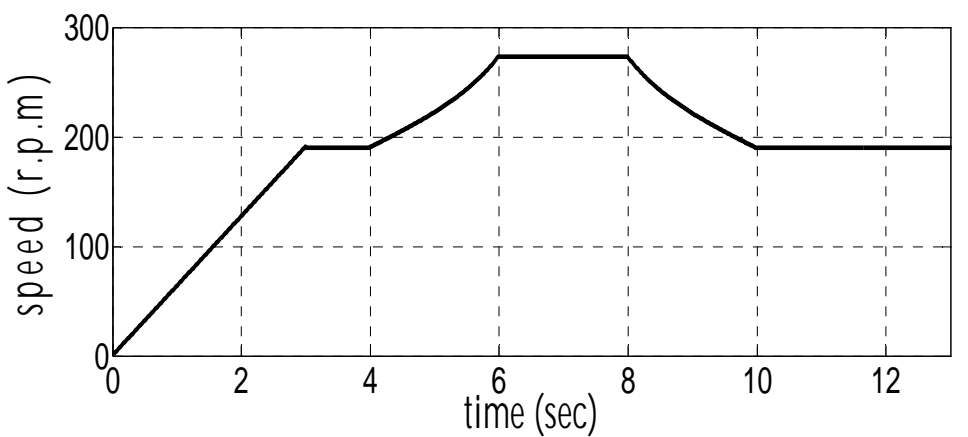

(c)

right wheel
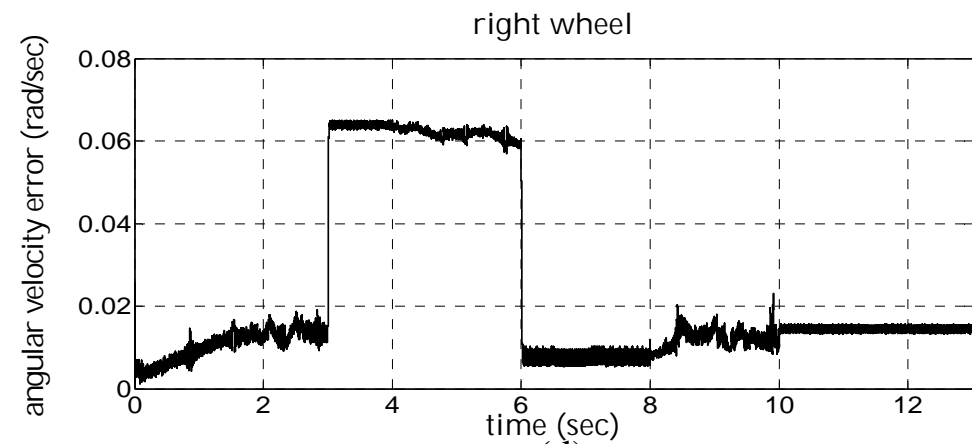

(d)

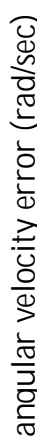

left wheel

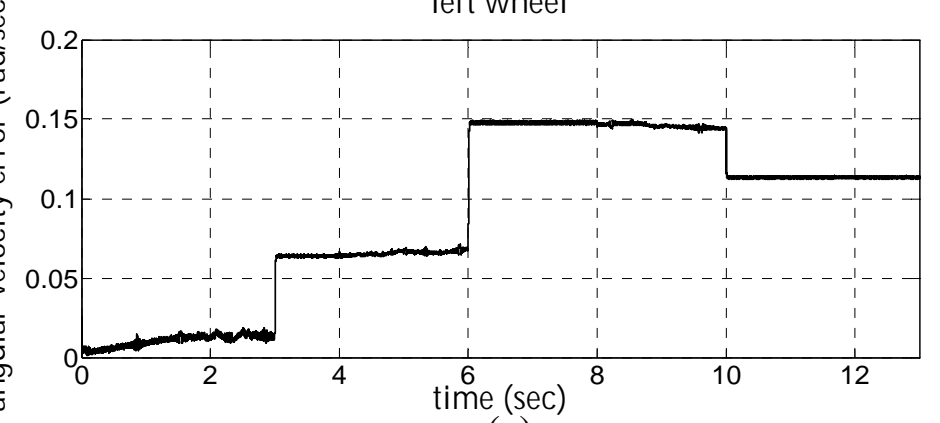

(e)

Fig 12: Simulation result when vehicle turn to right.

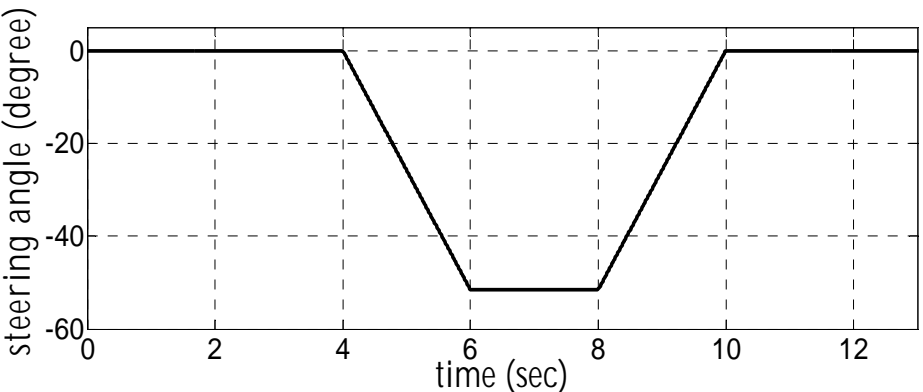

(a)

right wheel

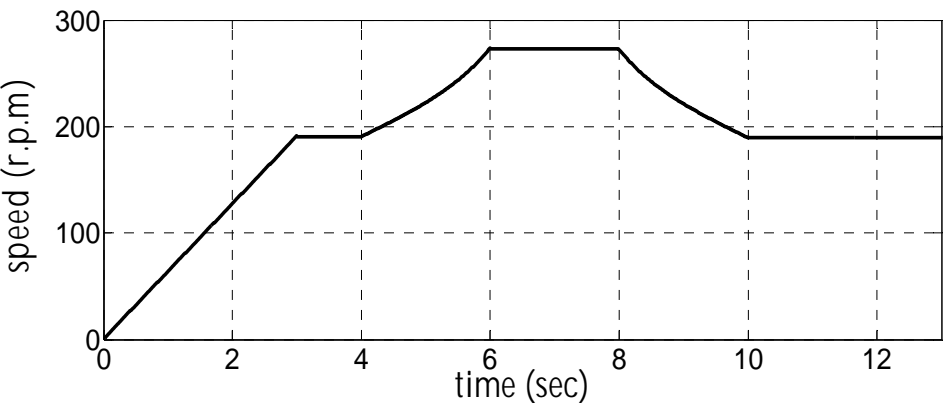

(b)

left wheel

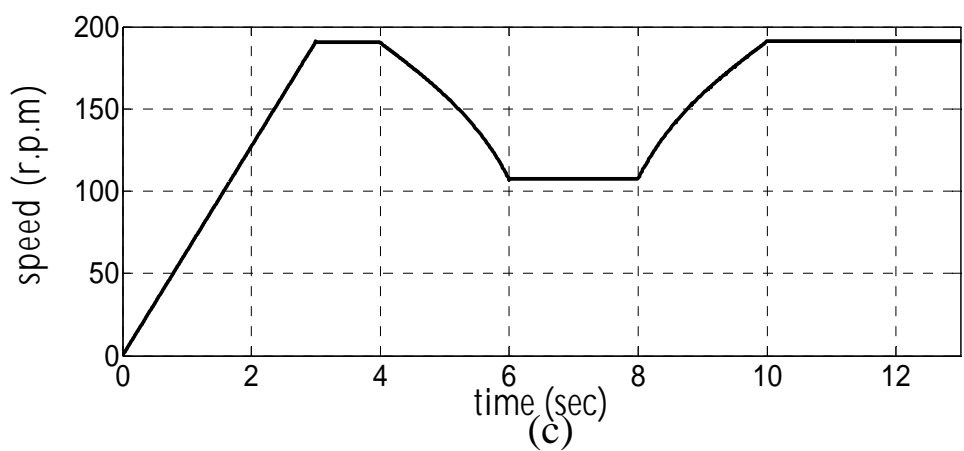

right wheel

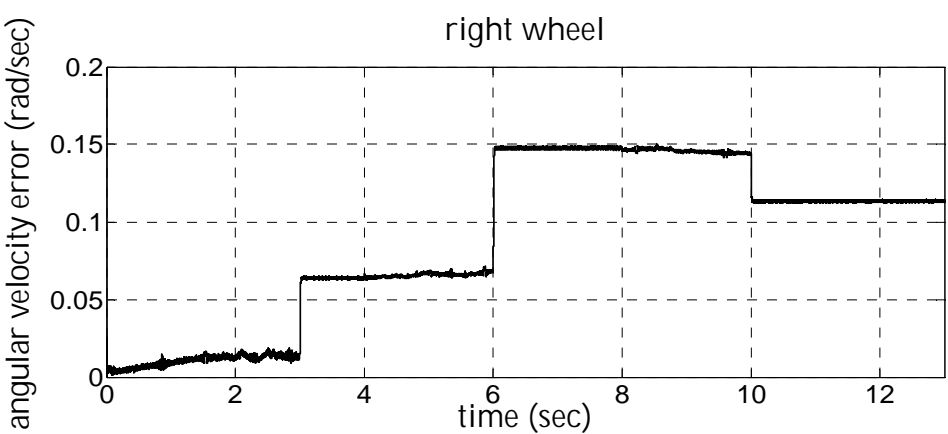

(d)

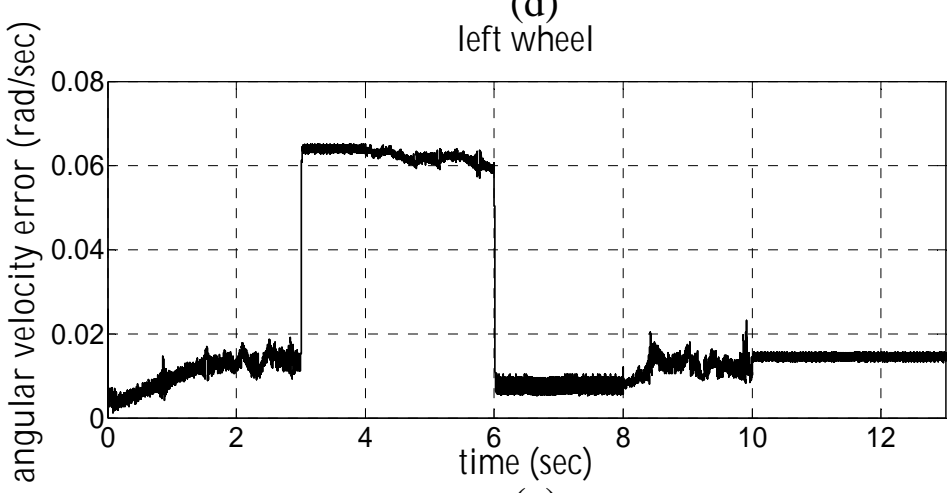

(e)

Fig 13: Simulation result when vehicle turn to left. 


\section{CONCLUSIONS}

This paper presented an electric vehicle with two independent rear wheel drives. An electrical differential with suitable control system was implemented assuring that, in straight right trajectory, the two rear wheels roll exactly at same speed (for steering angle ( $\delta=0$ ) and for the same road conditions under the left and right side wheels, also for the same condition but variable steering angle to make vehicle turn to left and to right. In addition, this paper demonstrate the motor tested with two different subclasses of four quadrant of DC/DC chopper voltage and declare a complete study of the method for developing energy saving. The system analysis, modeling and simulation are presented. finally, this paper demonstrate control system is simpler than control system that demonstrate in paper [3] in addition with sensor control the speed error between reference and actual speed around zero and the controller used is not only suitable to control speed of the vehicle, but also to control the motor current.

\section{REFERENCES}

[1] Foito,D.; Roque, A.; Esteves, J.; Maia, J.: Electric Vehicle With Two Independent Wheel Drives - Improving The Performance With a Traction Control System, Proceedings of EVS 17, Montreal, Oct.2000

[2] Roque, A.; Esteves, J.; Maia, J.; Verdelho, P.: Analysis and design of a traction control algorithm for an electric kart with two independent wheel drives, Electrimacs 99.

[3] Codeiro,A. Foito,D. Guerreiro,M.: A sensorless speed control system for an electric vehicle without mechanical differential gear, IEEE Melecon 2006,spain.

[4] Wong, J.Y.;The theory of ground vehicles, John Wiley \& sons, Inc., 1993, ISBN 0-471-52496-4.

[5] Gillespie, Thomas. Fundamentals of Vehicle Dynamics, Society of Automotive Engineers, ISBN 1-56091-199-9.

[6] Hori, Y.; Toyoda, Y.; Tsuruoka, Y.: Traction control of electric vehicle: Basic experimental results using the test EV - UOT Electric March, IEEE Trans. on Industry Applications, vol. 34, n. 5, September/October 1998.

[7] Foito,D.; Roque, A.; Esteves, J.; Maia, J.: Electric Vehicle With Two Independent Wheel Drives - Improving The Performance With a Traction Control System, Proceedings of EVS 17, Montreal, Oct.2000 